\title{
Влияние термического отжига на фотолюминесценцию структур c InGaAs/GaAs квантовыми ямами и низкотемпературным $\delta$-легированным Mn слоем GaAs
}

\author{
(С) И.Л. Калентьева ${ }^{+}$, О.В. Вихрова ${ }^{+}$, Ю.А. Данилов ${ }^{+}$, Б.Н. Звонков ${ }^{+}$, А.В. Кудрин ${ }^{+}$, М.Н. Дроздов* \\ + Научно-исследовательский физико-технический институт \\ Нижегородского государственного университета им. Н.И. Лобачевского, \\ 603950 Нижний Новгород, Россия \\ * Институт фризики микроструктур Российской академии наук, \\ 603950 Нижний Новгород, Россия \\ E-mail: istery@rambler.ru
}

(Получена 27 апреля 2016 г. Принята к печати 10 мая 2016 г.)

Исследовано влияние термических изохронных отжигов $\left(325-725^{\circ} \mathrm{C}\right)$ на излучательные свойства $\mathrm{InGaAs} / \mathrm{GaAs}$ гетеронаноструктур, содержащих низкотемпературный $\delta$-легированный Mn слой GaAs, выращенный методом лазерного осаждения. Наблюдается спад интенсивности фотолюминесценции и увеличение энергии основного перехода при термическом воздействии для квантовых ям, расположенных вблизи низкотемпературного слоя $\mathrm{GaAs}$. Вторичной ионной масс-спектрометрией получено распределение атомов Мn в исходных и отожженных структурах. Обсуждается качественная модель наблюдаемого влияния термического отжига на излучательные свойства структур, которая учитывает наличие двух основных процессов: диффузии точечных дефектов (в первую очередь вакансий галлия) из покровного слоя GaAs в глубь структуры и диффузии $\mathrm{Mn}$ в обоих направлениях по диссоциативному механизму. Исследования намагниченности показали, что в результате термических отжигов происходит возрастание доли ферромагнитной при комнатной температуре фазы (предположительно, кластеров $\mathrm{MnAs}$ ) в низкотемпературном покровном слое.

\section{1. Введение}

Гетероструктуры с квантовыми ямами (КЯ) InGaAs/GaAs, содержащие $\delta$-легированный марганцем слой $\mathrm{GaAs}$, являются перспективными для создания современных приборов спинтроники, таких как спиновые светоизлучающие диоды, поскольку обладают достаточно высокой интенсивностью излучения и ферромагнитными свойствами [1]. Для получения структур применяется комбинированный метод МОС-гидридной эпитаксии (МОСГЭ) и импульсного лазерного осаждения (ЛО) [2]. Использование приема $\delta$-легирования марганцем для формирования гетеронаноструктур осуществляется при значительном понижении температуры в процессе лазерного нанесения $\delta$-слоя $\mathrm{Mn}$ и последующего слоя GaAs [2]. Это позволяет подавить диффузию марганца и сохранить дельтообразный вид распределения примеси, но, в свою очередь, может способствовать возникновению дефектов в низкотемпературном слое GaAs. В итоге присутствие дефектов и их возможная диффузия при послеростовых операциях изготовления (например, при термической обработке после нанесения металлических контактов) может негативно сказываться на электрических и излучательных характеристиках спиновых светоизлучающих диодов.

С другой стороны, как известно, квантово-размерные структуры могут применяться для изучения процессов дефектообразования [3]. Эта возможность основана на использовании квантовых ям, встроенных в базовый полупроводник на достаточно малых расстояниях от поверхности, в качестве зондов, реагирующих на появление в окрестности ям дефектов, изменяющих реком- бинационные характеристики квантовой ямы. Встраивая в полупроводник несколько квантовых ям различного состава или ширины для идентификации ям по спектру фотолюминесценции (ФЛ), можно получить информацию о пространственном распределении дефектов в структуре. Также известно, что напряженные квантоворазмерные гетерослои могут задерживать диффузию дефектов в объемный слой полупроводника. Как показано в работе [4], встроенные в приповерхностной области слоя $\mathrm{GaAs}$ квантовые ямы InGaAs/GaAs задерживают диффузию водорода и генерируемых на поверхности дефектов в объем.

В связи со сказанным представляются актуальными результаты исследований влияния изохронного термического отжига на фотолюминесцентные свойства структур с квантовыми ямами InGaAs/GaAs, $\delta$-слоем марганца и низкотемпературным покровным слоем GaAs. Основные наблюдаемые эффекты связываются с процессами диффузии марганца и точечных дефектов.

\section{2. Методики изготовления и исследования структур}

Исследуемые нами гетеронаноструктуры $\mathrm{InGaAs} / \mathrm{GaAs}$ с $\delta$-слоем марганца были получены на подложках $n$-GaAs (001) методом, сочетающим MOCгидридную эпитаксию и лазерное осаждение в едином ростовом цикле [2]. Буферный слой GaAs толщиной 0.5 мкм, три квантовые ямы $\operatorname{In}_{x} \mathrm{Ga}_{1-x} \mathrm{As} / \mathrm{GaAs}$ шириной $8-9$ нм с содержанием индия $x=0.11,0.18$ и 0.26 , разделенные слоями GaAs толщиной 24 нм, спейсерный 
Основные технологические параметры формирования гетеронаноструктур InGaAs/GaAs

\begin{tabular}{c|c|c|c|c}
\hline № & $Q_{\text {Mn }, \text { MC }}$ & $d_{s}$, нм & $\begin{array}{c}\text { Температура } \\
\text { роста покров- } \\
\text { ного слоя, }{ }^{\circ} \mathrm{C}\end{array}$ & $\begin{array}{c}\text { Метод выращива- } \\
\text { ния покровного } \\
\text { слоя }\end{array}$ \\
\hline 1 & 0 & 12 & 400 & ЛО \\
2 & 0 & - & 600 & МОСГЭ \\
3 & 0.3 & 12 & 400 & ЛО \\
4 & 1 & 12 & 400 & ЛО
\end{tabular}

слой $\mathrm{GaAs}$ толщиной $d_{s}$, разделяющий $\delta$-слой $\mathrm{Mn}$ и ближайшую квантовую яму, выращивались при $600^{\circ} \mathrm{C}$ методом МОС-гидридной эпитаксии. Расположенная ближе всего к поверхности квантовая яма содержала наибольшее количество индия. Далее температура роста $\left(T_{g}\right)$ понижалась до $400^{\circ} \mathrm{C}$ и методом импульсного лазерного осаждения формировались $\delta$-слой Мn и покровный слой $\mathrm{GaAs}$ толщиной $\sim 30-40$ нм. Содержание $\mathrm{Mn}$ в $\delta$-слое $\left(Q_{\mathrm{Mn}}\right)$ в одном образце составляло 0.3 монослоя (MC), в другом - 1 МС. Один монослой соответствует слоевой концентрации атомов марганца $6.3 \cdot 10^{14} \mathrm{~cm}^{-2}$.

Аналогичным способом были выращены структуры без $\delta$-слоя $\mathrm{Mn}$, отличающиеся между собой температурой и способом формирования покровного слоя. Основные технологические параметры получения структур представлены в таблице. В случае контрольной структуры 1 указанный спейсер GaAs толщиной $d_{s}$ разделял ближайшую к поверхности квантовую яму и низкотемпературный покровный слой GaAs.

Bce гетеронаноструктуры подвергались изохронному термическому отжигу в течение 30 мин в потоке азота в диапазоне температур $\left(T_{a}\right) 325-725^{\circ} \mathrm{C}$ с шагом по температуре в $25^{\circ} \mathrm{C}$. После каждого этапа отжига исследовались излучательные характеристики структур методом спектроскопии фотолюминесценции при $77 \mathrm{~K}$. Для возбуждения излучения использовался $\mathrm{He}-\mathrm{Ne}$-лазер (длина волны $=632.5 \mathrm{Hм}$ ) с мощностью 30 мВт. Исследования структур методом вторичной ионной масс-спектрометрии (ВИМС) были выполнены на установке TOF.SIMS-5. Послойный анализ проводился с использованием распыляющих пучков ионов $\mathrm{O}_{2}$ или Cs и анализирующего пучка ионов $\mathrm{Bi}$. Глубина и размеры кратеров травления измерялись с помощью интерференционного микроскопа Talysurf CCI 2000 [5]. Исследования намагниченности структур проводилось при комнатной температуре при помощи магнитометра переменного градиента поля [6].

\section{3. Экспериментальные результаты и обсуждение}

Вначале были исследованы спектры фотолюминесценции всех перечисленных структур (см. таблицу) в исходном состоянии, т. е. без термического воздействия.
Как видно из вставки к рис. 1, спектры фотолюминесценции исходных образцов содержали три пика, соответствующих энергиям основных переходов в трех квантовых ямах.

Из представленных данных можно заключить, что понижение температуры роста покровного слоя GaAs до $400^{\circ} \mathrm{C}$ и присутствие в нем $\delta$-слоя $\mathrm{Mn}$ с $Q_{\mathrm{Mn}}=0.3 \mathrm{MC}$ практически не оказало влияния на светоизлучающие характеристики гетеронаноструктур. Это позволяет предположить сохранение достаточно хорошего кристаллического качества низкотемпературного покровного слоя $\mathrm{GaAs}$ даже при условии легирования его небольшим количеством марганца.

Напротив, наличие $\delta$-слоя с большим содержанием $\mathrm{Mn}(\sim 1 \mathrm{MC})$ в покровном слое $\mathrm{GaAs}$ (образец 4) приводит к значительному уменьшению интенсивности пика, отвечающего основному переходу в квантовой яме (QW3), ближайшей по расположению к $\delta$-слою $\mathrm{Mn}$. Для двух других квантовых ям (QW1 и QW2) спада интенсивности излучения по отношению к тестовому образцу 1 не наблюдается. По-видимому, такой эффект обусловлен увеличением количества центров безызлучательной рекомбинации, возникающих вследствие избыточного содержания марганца. Так, в [7] было показано, что концентрация Mn в один монослой является критической, и при $Q_{\mathrm{Mn}} \geq 1 \mathrm{MC}$ в $\mathrm{GaAs}$ возникают дислокации и наблюдается поверхностная сегрегация марганца.

Исследования излучательных характеристик структур после проведения термических обработок обнаружили, что спектры фотолюминесценции в областях QW1 и QW2 практически не изменяются с увеличением температуры отжига, а все основные изменения происходят со спектром квантовой ямы, ближайшей по расположению к низкотемпературному покровному слою GaAs.

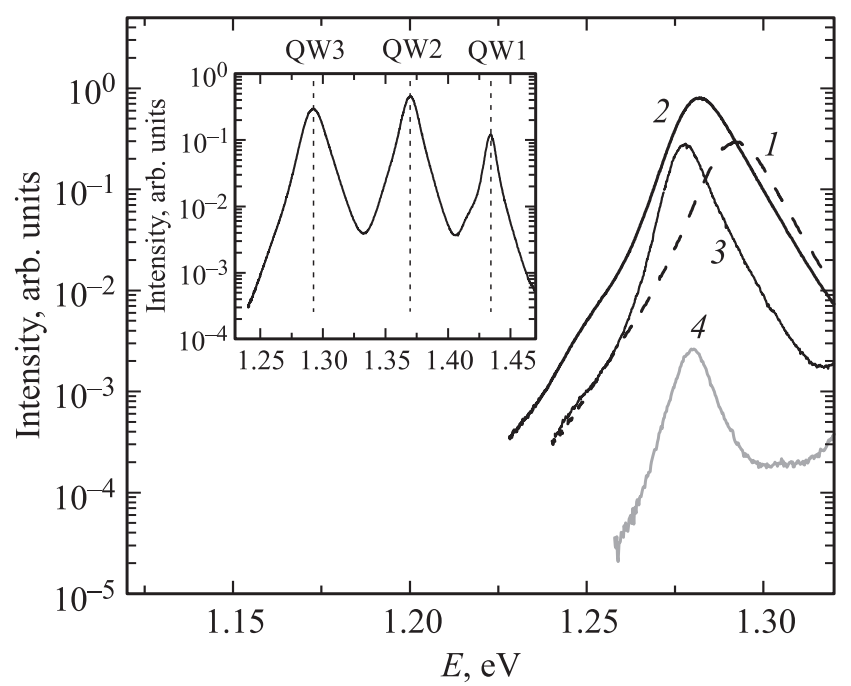

Рис. 1. Исходные спектры фотолюминесценции (77 K) гетеронаноструктур InGaAs/GaAs. Спектры 1,2, 3 и 4 соответствуют номерам структур, описание которых представлено в таблице. Представленный на вставке спектр соответствует структуре 1 . 

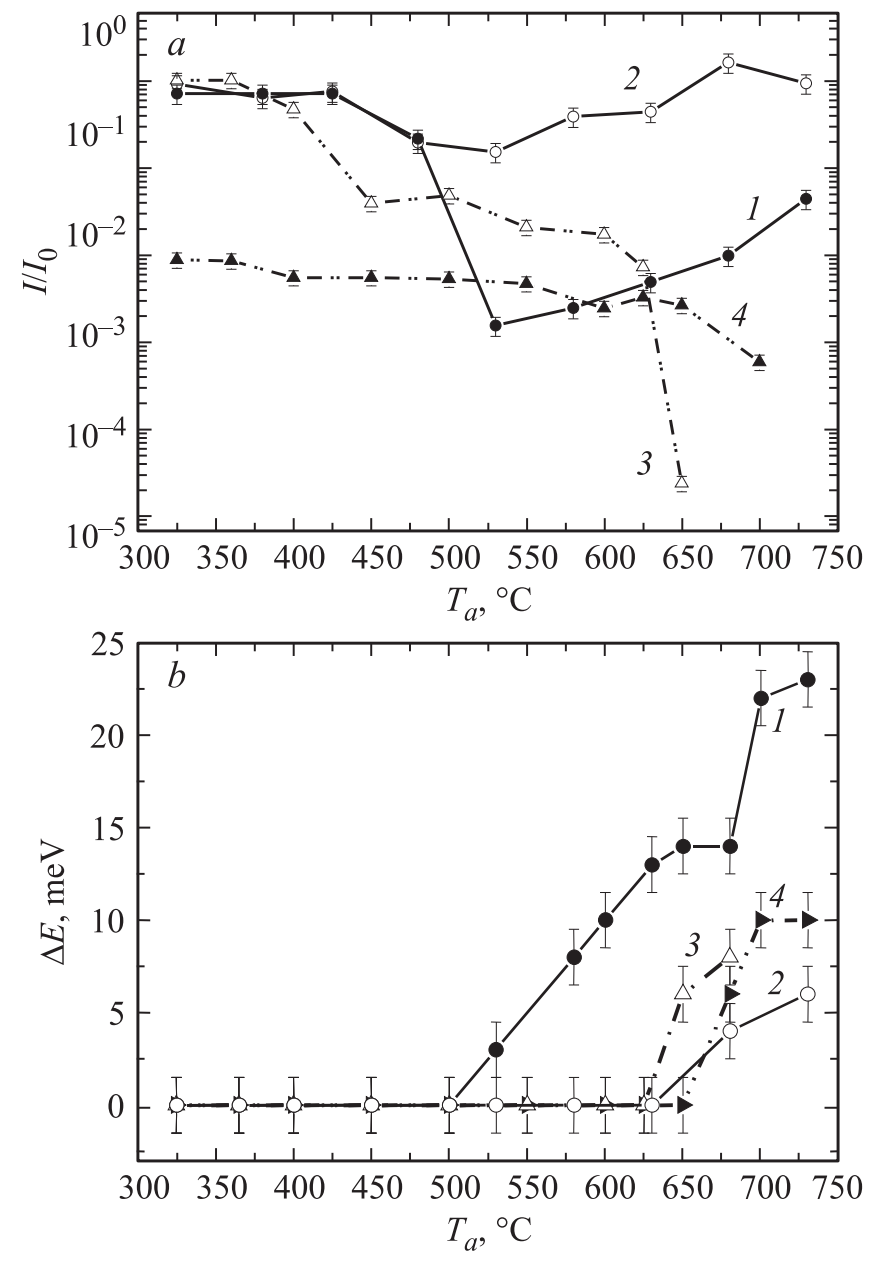

Pис. 2. $a-$ зависимости относительной интенсивности ФЛ излучения ближайшей к поверхности квантовой ямы QW3 от температуры отжига ( $I_{0}-$ интенсивность пика фотолюминесценции QW3 в исходном образце). $b$ - величина „синего“ сдвига пика фотолюминесценции QW3 при различных температурах отжига. Номера кривых совпадают с номерами соответствующих структур из таблицы.

Вначале сравним влияние термического отжига на излучательные свойства структур с высокотемпературным и низкотемпературным покровными слоями GaAs. Анализировались зависимости относительной интенсивности фотолюминесцентного излучения QW3 от температуры отжига $\left(I / I_{0}\left(T_{a}\right)\right.$, где $I_{0}$ - интенсивность ФЛ квантовой ямы исходного образца структуры и изменение энергии основного перехода QW3 при термическом воздействии. Из сопоставления зависимостей $I / I_{0}\left(T_{a}\right)$ для структур 1 и 2, не содержащих Mn и отличающихся температурой формирования покровного слоя GaAs (рис. 2, a, кривые 1 и 2 соответственно), видно, что в диапазоне температур от 475 до $525^{\circ} \mathrm{C}$ интенсивность фотолюминесценции QW3 структуры 1 уменьшается более чем на 2 порядка величины. При температурах свыше $525^{\circ} \mathrm{C}$ регистрируется частичное восстановление сигнала фотолюминесценции QW3. Кроме того, начиная с температуры отжига $\sim 525^{\circ} \mathrm{C}$ регистрируется значительный сдвиг пика фотолюминесценции QW3 в область больших энергий $(\Delta E)$. Величина $\Delta E$ достигает 22 мэВ при $T_{a}=700^{\circ} \mathrm{C}$ (рис. 2, $b$, кривая 1 ).

Термообработка структуры 2 (высокотемпературный покровный слой $\mathrm{GaAs}$ ) показывает (рис. 2, $a$, кривая 2), что значительных изменений в интенсивности излучения QW3 при $475 \leq T_{a} \leq 525^{\circ} \mathrm{C}$ не происходит. Отсутствуют также необратимые изменения интенсивности вплоть до отжига при $725^{\circ} \mathrm{C}$ и, начиная с температуры отжига $675^{\circ} \mathrm{C}$, наблюдается гораздо меньший сдвиг $\Delta E(4$ мэВ при $\left.700^{\circ} \mathrm{C}\right)$.

Наблюдаемые сильный спад интенсивности фотолюминесценции и значительный „синий“ сдвиг соответствующего пика QW3 в спектре образца 1 с низкотемпературным покровным слоем, по-видимому, обусловлены диффузией точечных дефектов из низкотемпературного покровного слоя, полученного методом лазерного осаждения, в активную область структуры. Как и в случае выращенных методом низкотемпературной молекулярно-лучевой эпитаксии (МЛЭ) слоев GaAs, здесь основными точечными дефектами могут быть антиструктурные дефекты $\left(\mathrm{As}_{\mathrm{Ga}}\right)$, междоузельные атомы мышьяка $\left(\mathrm{As}_{i}\right)$ и вакансии галлия $\left(V_{\mathrm{Ga}}\right)$ [8]. В частности, изучение фотоэлектрических свойств образца $1 \mathrm{c}$ низкотемпературным покровным слоем GaAs показало наличие EL2-центров с глубиной залегания 0.75 эB [9]. Предполагается, что EL2-центры представляют собой изолированные, либо связанные в пары с $\mathrm{As}_{i}$ или $V_{\mathrm{Ga}}$ антиструктурные дефекты мышьяка [10].

Как известно, вакансии галлия являются центрами безызлучательной рекомбинации в GaAs [11] и активизируют перемешивание атомов In и $\mathrm{Ga}$ на границе InGaAs/GaAs в процессе термического отжига. В результате происходит изменение профиля квантовой ямы, она становится эффективно мельче, а в спектре фотолюминесценции наблюдается „синий“ сдвиг [12]. Подобные процессы перемешивания квантовых ям могут быть индуцированы протонным облучением [12] или нанесением на поверхность структуры диэлектрического слоя $\mathrm{SiO}_{2}$ [13]. В случае наличия на поверхности структуры слоя $\mathrm{SiO}_{2}$ при соответствующей термической обработке атомы галлия движутся к поверхности, а вакансии галлия диффундируют вглубь структуры и вызывают перемешивание на границах квантовых ям [13].

Можно полагать, что в нашем случае наблюдаемые сильные изменения спектра фотолюминесценции QW3 связаны с диффузионным проникновением избыточных $V_{\mathrm{Ga}}$ из низкотемпературного покровного слоя в QW3. Монотонный рост интенсивности фотолюминесценции после отжигов при температурах $\geq 525^{\circ} \mathrm{C}$ объясняется тем, что полное количество $V_{\mathrm{Ga}}$ составляет $\left[V_{\mathrm{Ga}}\right] \cdot d_{\mathrm{GaAs}}$ $\left(d_{\mathrm{GaAs}}\right.$ - толщина сформированного ИЛО покровного слоя $\mathrm{GaAs}$ ), и мы имеем дело с диффузией вакансий из ограниченного источника, что приводит к размыванию профиля по всей структуре с понижением концентрации $V_{\mathrm{Ga}}$ в области QW3. „Синий“ сдвиг положения пика ФЛ 
QW3 структуры 1 начинается с температуры отжига $525^{\circ} \mathrm{C}$, что связано с перемешиванием границы раздела из-за прибытия вакансий из низкотемпературного покровного слоя GaAs. Гораздо меньший сдвиг в области температур свыше $625^{\circ} \mathrm{C}$ для структуры 2 связан, по нашему мнению, с увеличением в области границы раздела GaAs/InGaAs во время отжига концентрации термически равновесных вакансий галлия, которая при охлаждении структуры возвращается к равновесному значению (не сказывается на интенсивности фотолюминесценции).

Теперь перейдем к сравнительному анализу термического воздействия на излучательные свойства структур 1 и 3,4 , отличающихся отсутствием или наличием $\delta$-слоя марганца в низкотемпературном покровном слое GaAs. Как было показано выше, введение примеси в количестве $Q_{\mathrm{Mn}}=0.3 \mathrm{MC}$ не оказало влияния на величину сигнала фотолюминесценции QW3 исходных образцов структур. Вместе с тем характер зависимостей относительной интенсивности фотолюминесцентного излучения QW3 от температуры отжига меняется, когда в низкотемпературном покровном слое GaAs присутствует $\delta$-слой $\mathrm{Mn}$. Для образца с $Q_{\mathrm{Mn}}=0.3 \mathrm{MC}$ наблюдается монотонный спад интенсивности фотолюминесценции QW3 во всем диапазоне температур вплоть до полного гашения излучения при $600<T_{a}<700^{\circ} \mathrm{C}$ (кривая 3, рис. 2,a). В случае структуры 4 сигнал ФЛ QW3 также снижается в процессе отжигов, но наблюдается интересная особенность: излучение квантовой ямы QW3, ослабленное в результате введения в исходную структуру $\delta$-слоя $\mathrm{Mn} \mathrm{c} Q_{\mathrm{Mn}}=1 \mathrm{MC}$, регистрируется вплоть до самых высоких температур отжига. Кроме того, для образцов с $\delta$-слоем марганца сдвиг пика фотолюминесценции QW3 в область больших энергий начинает появляться при температурах отжига свыше 625-650 ${ }^{\circ} \mathrm{C}$, подобно структуре 2 с высокотемпературным слоем GaAs. Величина смещения составляет 8 мэВ в случае образца с $Q_{\mathrm{Mn}}=0.3 \mathrm{MC}$ и 6 мэВ для образца с $Q_{\mathrm{Mn}}=1 \mathrm{MC}$ (рис. 2,b).

Обсудим, что происходит в структурах при введении $\delta$-слоя $\mathrm{Mn}$. Когда $Q_{\mathrm{Mn}}=0.3 \mathrm{MC}$, концентрация атомов $\mathrm{Mn}$ в максимуме распределения, согласно данным ВИМС, достигает $\sim 1 \cdot 10^{20} \mathrm{~cm}^{-3}[14]$. Можем полагать, что большая часть атомов $\mathrm{Mn}$ находится в узлах $\mathrm{Ga}$. При увеличении $Q_{\mathrm{Mn}}$ до $1 \mathrm{MC}$ объемная концентрация атомов Mn в максимуме распределения практически не увеличивается по сравнению со случаем $Q_{\mathrm{Mn}}=0.3 \mathrm{MC}$. Избыточный марганец $(0.7 \mathrm{MC})$ испытывает сегрегацию и фронтом роста эпитаксиальной структуры 4 смещается к поверхности [14]. Мы полагаем, что имеется также поток межузельных атомов $\mathrm{Mn}_{i}$ вглубь структуры при температуре выращивания $T_{g}=400^{\circ} \mathrm{C}$ [15]. Междоузельный марганец, который является центром безызлучательной рекомбинации в соединениях на основе GaAs [16], диффундирует вглубь структуры и достигает квантовой ямы за время формирования покровного слоя GaAs. Это

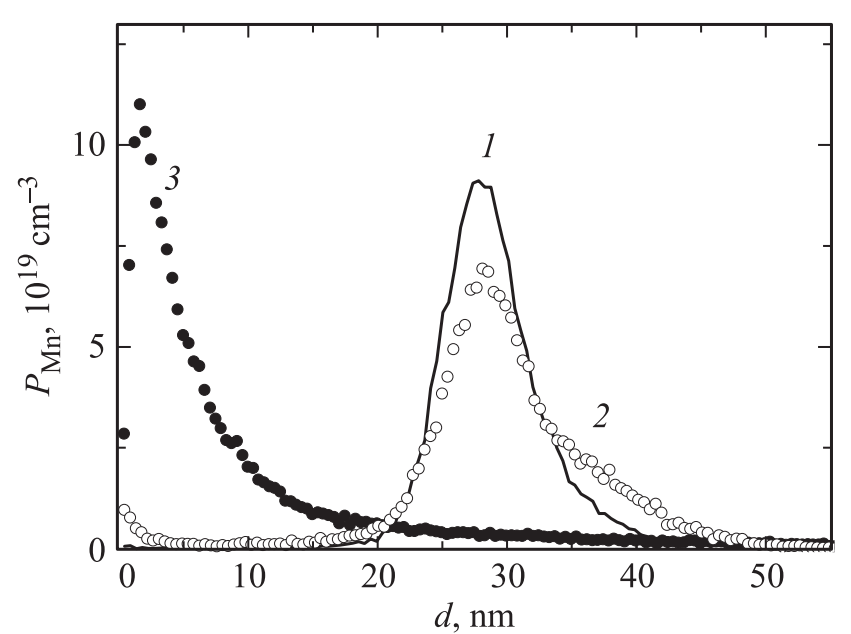

Рис. 3. ВИМС профили распределения атомов $\mathrm{Mn}$ по глубине структуры с $Q_{\text {Мn }}=0.12$ МС. 1 - исходный образец, $2-$ отожженный при $T_{a}=425^{\circ} \mathrm{C}, 3-$ отожженный при $T_{a}=730^{\circ} \mathrm{C}$.

может быть причиной наблюдаемого уменьшения интенсивности фотолюминесценции квантовой ямы QW3 для исходной структуры 4 с $Q_{\mathrm{Mn}}=1 \mathrm{MC}$ по сравнению с ФЛ структуры 3 (рис. 1).

Термическое воздействие приводит к расплыванию $\delta$-слоя вследствие значительного увеличения коэффициента диффузии марганца с ростом температуры отжига. Причем, как видно по результатам исследования образцов методом вторичной ионной масс-спектрометрии (рис. 3), процесс диффузии марганца в покровный низкотемпературный слой может преобладать над процессом диффузии в объем структуры. Методом ВИМС были исследованы три образца структуры, подобной структуpe 3 , но с содержанием $\mathrm{Mn}$ в $\delta$-слое $0.12 \mathrm{MC}$ : исходный образец и образцы, отожженные при 425 и $700^{\circ} \mathrm{C}$. Для исходного образца профиль распределения атомов $\mathrm{Mn}$ в $\delta$-слое представляет собой практически симметричное распределение по глубине относительно положения $\delta$-слоя (ширина пика на полувысоте составляет порядка 6 нм). После отжига при температуре $425^{\circ} \mathrm{C}$ наблюдается диффузия марганца вглубь структуры. Кроме того, наблюдается проникновение атомов $\mathrm{Mn}$ в покровный слой GaAs и их накопление вблизи поверхности структуры. Процесс отжига при $730^{\circ} \mathrm{C}$ существенным образом усиливает эту тенденцию: основная часть атомов $\mathrm{Mn}$ сосредоточивается вблизи поверхности.

Атомы марганца диффундируют в GaAs по диссоциативному механизму, т.е. могут занимать как позиции в узлах $\mathrm{Ga}\left(\mathrm{Mn}_{\mathrm{Ga}}\right)$, так и в междоузлиях $\left(\mathrm{Mn}_{i}\right)$, с обменом атомами Mn между этими положениями; при этом концентрация $\mathrm{Mn}_{i}$ значительно ниже концентрации $\mathrm{Mn}_{\mathrm{Ga}}$ [17]. Присутствие точечных дефектов в GaAs, в частности вакансий галлия, играет важную роль в процессе диффузии марганца. Согласно данным позитронной аннигиляционной спектроскопии, приведенным в [18], в случае получения слоя $\mathrm{GaAs}$ при $400^{\circ} \mathrm{C}$ методом 
молекулярно-лучевой эпитаксии (МЛЭ), минимальная концентрация $V_{\mathrm{Ga}}$ может составлять порядка $10^{16} \mathrm{~cm}^{-3}$. Поскольку процесс лазерного осаждения является более неравновесным, чем МЛЭ, и возможны отклонения от стехиометрии, можно полагать, что концентрация вакансий может превышать это значение. Согласно оценкам, сделанным нами по формулам, приведенным в $[19,20]$, соответственно коэффициент диффузии марганца и коэффициент диффузии вакансий галлия сопоставимы по порядку величины в температурном диапазоне от 425 до $730^{\circ} \mathrm{C}$ и увеличиваются от $\sim 10^{-18}$ до $10^{-14} \mathrm{~cm}^{2} / \mathrm{c}$. Следовательно, можно допустить, что с повышением температуры отжига исследуемых нами гетеронаноструктур наблюдаемый преимущественный процесс диффузии марганца к поверхности обусловлен присутствием вакансий галлия. На наш взгляд, поток $V_{\mathrm{Ga}}$ из покровного слоя встречает атомы марганца; за счет этого при отжиге происходит перераспределение атомов $\mathrm{Mn}$ из $\delta$-слоя к поверхности структуры (см. рис. 3). Вакансии галлия дальше $\delta$-слоя практически не проникают. Обратим внимание, что „синий“ сдвиг пика ФЛ для легированных Мn структур 3 и 4 начинается в результате отжига при температурах выше $650^{\circ} \mathrm{C}$, поэтому, как и в случае структуры 2 с высокотемпературным покровным слоем $\mathrm{GaAs}$, он может быть обусловлен присутствием термически равновесных вакансий галлия. Принимая во внимание вышеизложенное, естественно полагать, что поток избыточных вакансий галлия из низкотемпературного покровного GaAs слоя не достигает QW3 в структурах с $\delta$-слоем марганца.

Монотонное уменьшение интенсивности излучения QW3 для структуры 3 можно объяснить диффузией $\mathrm{Mn}_{i}$ из более глубокой части $\delta$-слоя по направлению к QW3. Интенсивность фотолюминесцентного пика QW3 для структуры 4 меняется не сильно, поскольку там уже имеется почти предельная концентрация междоузельного марганца.

Анализ электрических свойств $\delta$-легированных марганцем структур в зависимости от содержания $\mathrm{Mn}$, сделанный нами ранее [14], показал, что, начиная с $Q_{\mathrm{Mn}} \geq 0.3 \mathrm{MC}$, наблюдается насыщение слоевой концентрации носителей заряда (дырок) $\left(p_{s}=5 \cdot 10^{13} \mathrm{~cm}^{-2}\right.$ при $\left.300 \mathrm{~K}\right)$. Подвижность дырок уменьшалась от $80 \mathrm{~cm}^{2} /(\mathrm{B} \cdot \mathrm{c})$ (при $Q_{\mathrm{Mn}}=0.06 \mathrm{MC}$ ) до $20 \mathrm{~cm}^{2} /(\mathrm{B} \cdot \mathrm{c})$ (при $Q_{\mathrm{Mn}}=0.3 \mathrm{MC}$ ) и далее с повышением содержания $\mathrm{Mn}$ оставалась неизменной. Следовательно, избыточный марганец находится в компенсированном и(или) электрически неактивном состоянии.

Компенсация дырочной проводимости может происходить из-за возрастания доли атомов марганца, занимающих межузельные положения и являющихся двойными донорами [21]. Кроме того, согласно исследованиям [22], при увеличении концентрации марганца от 0 до $5 \%$ в однородно легированных слоях $\mathrm{GaMnAs}$ возрастает количество антиструктурных дефектов донорного типа (атом мышьяка в положении галлия), вследствие чего также происходит компенсация дырочной проводимости.

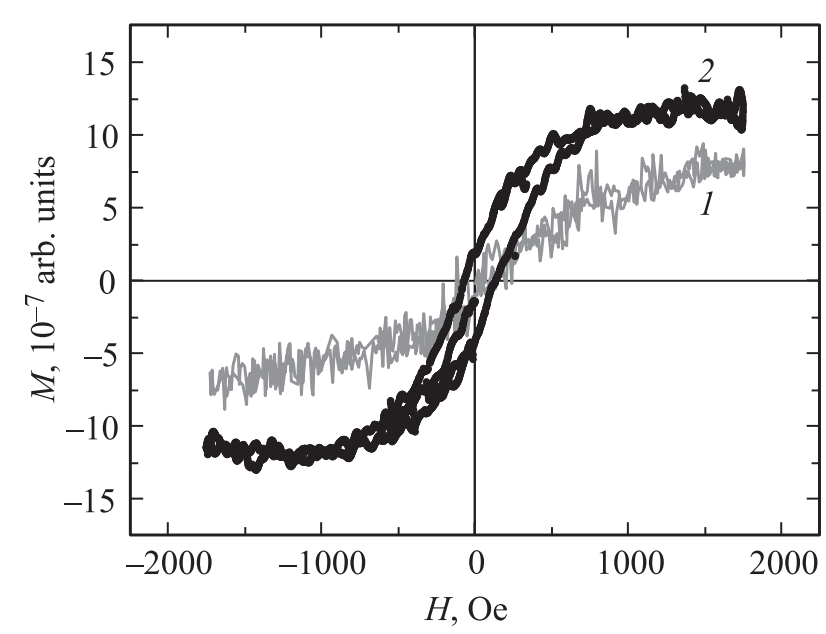

Рис. 4. Магнитополевая зависимость намагниченности при $300 \mathrm{~K}$ для структуры с $T_{g}=400^{\circ} \mathrm{C}$ и $Q_{\mathrm{Mn}}=0.3 \mathrm{MC}: 1-$ исходный образец, $2-$ отожженный при $T_{a}=725^{\circ} \mathrm{C}$. Магнитное поле приложено в плоскости образца.

Электрически неактивное состояние марганца связывают главным образом с образованием в полупроводнике GaMnAs кластеров полуметаллических ферромагнитных соединений (MnAs) с температурой Кюри выше комнатной [23]. Высокотемпературный отжиг слоев GaMnAs способствует этому процессу [24]. Мы попытались понять, в каком состоянии может находиться избыточная примесь марганца, введенная в процессе формирования $\delta$-легированных слоев GaAs c $Q_{\mathrm{Mn}} \geq 0.3 \mathrm{MC}$, и что происходит с ней после цикла проведенных термических отжигов. С этой целью было проведено исследование магнитополевых зависимостей намагниченности $(M(H))$ при комнатной температуре структур 3 и 4 в исходном состоянии и после отжига $\left(T_{a}=725^{\circ} \mathrm{C}\right)$. Полученные результаты представлены на рис. 4. Зависимость $M(H)$ исходного образца имеет нелинейный вид. После термического отжига нелинейный характер магнитополевой зависимости намагниченности сохраняется, увеличивается величина намагниченности насыщения и появляется петля гистерезиса. Наблюдаемые эффекты свидетельствуют об „усилении“ ферромагнитных свойств, связанном с возрастанием в образце доли ферромагнитной фазы (кластеров MnAs) c температурой Кюри выше комнатной.

\section{4. Заключение}

Таким образом, проведенные нами исследования показали, что в гетеронаноструктурах $\mathrm{InGaAs} / \mathrm{GaAs}$ с низкотемпературным $\delta$-легированным марганцем слоем GaAs, выращенным методом лазерного осаждения, изохронный термический отжиг в потоке азота в диапазоне температур $325-725^{\circ} \mathrm{C}$ способствует следующим процессам:

(1) диффузии точечных дефектов (в первую очередь вакансий галлия) из покровного слоя в глубь структуры, 
поскольку низкотемпературный покровный слой $\mathrm{GaAs}$ является источником избыточных (по сравнению с равновесным значением) вакансий галлия;

(2) диффузии марганца к поверхности и в глубь структуры, причем, в связи с присутствием избыточной концентрации вакансий галлия наблюдается преимущественное движение атомов $\mathrm{Mn}$ в покровный низкотемпературный слой, в результате чего задерживается проникновение вакансий галлия в область квантовой ямЫ.

Процесс (1) наиболее ярко выражен для структур с низкотемпературным покровным слоем GaAs без $\delta$-слоя Mn. В данном случае вакансии галлия, которые согласно литературным данным традиционно считаются центрами безызлучательной рекомбинации в $\mathrm{GaAs}$, достигают квантовой ямы, приводят к диффузионному перемешиванию In и $\mathrm{Ga}$, вследствие чего квантовая яма становится эффективно мельче, и в спектре фотолюминесценции наблюдается „синее“ смещение пика, отвечающего основному переходу в квантовой яме.

При анализе процесса (2) предполагалось, что атомы марганца диффундируют в GaAs по диссоциативному механизму, т. е. могут занимать как позиции в Ga-узлах $\left(\mathrm{Mn}_{\mathrm{Ga}}\right)$, так и в междоузлиях, с обменом атомами $\mathrm{Mn}$ между этими положениями; при этом концентрация $\mathrm{Mn}_{i}$ значительно ниже концентрации $\mathrm{Mn}_{\mathrm{Ga}}$. Основными центрами безызлучательной рекомбинации в квантовых ямах $\mathrm{GaAs} / \mathrm{InGaAs} / \mathrm{GaAs} \delta$-легированных марганцем структур являются вакансии галлия и межузельные атомы марганца. Результатом процесса (2) также является возрастание доли ферромагнитной при комнатной температуре фазы (предположительно, кластеров MnAs) в низкотемпературном покровном слое.

Работа выполнена в рамках реализации государственного задания (проекты № 8.1054.2014/К и 3.285.2014/K, 3423) Министерство образования и науки России, при поддержке РФФИ (гранты № 15-02-07824_a, 16-07-01102_a), стипендии (конкурс СП-2015) и гранта (МК-8221.2016.2) президента Российской Федерации.

\section{Список литературы}

[1] S.V. Zaitsev, V.D. Kulakovskii, M.V. Dorokhin, Yu.A. Danilov, P.B. Demina, M.V. Sapozhnikov, O.V. Vikhrova, B.N. Zvonkov. Physica E, 41, 652 (2009).

[2] Б.Н. Звонков, О.В. Вихрова, Ю.А. Данилов, Е.С. Демидов, П.Б. Демина, М.В. Дорохин, Ю.Н. Дроздов, В.В. Подольский, М.В. Сапожников. Опт. журн., 75 (6), 56 (2008).

[3] И.А. Карпович, А.В. Аншон, Н.В. Байдусь, Л.М. Батукова, Ю.А.Данилов, Б.Н. Звонков, С.М. Планкина. ФТП, 28, 104 (1994).

[4] И.А. Карпович, А.В. Аншон, Д.О. Филатов. ФТП, 32, 1089 (1998).

[5] R.T. Blunt. CS MANTECH Conf. (Vancouver, British Columbia, Canada) 59 (2006).

[6] P.J. Flanders. J. Appl. Phys., 63, 3940 (1988).
[7] A.M. Nazmul, S. Sugahara, M. Tanaka. J. Cryst. Growth, 251, 303 (2003).

[8] М.Д. Вилисова, А.Е. Куницын, Л.Г. Лаврентьева, В.В. Преображенский, М.А. Путято, Б.Р. Семягин, С.Е. Торопов, В.В. Чалдышев. ФТП, 36, 1025 (2002).

[9] А.П. Горшков, И.А. Карпович, Е.Д. Павлова, И.Л. Калентьева. ФТП, 46, 194 (2012).

[10] Ф.М. Воробкало, К.Д. Глинчук, А.В. Прохорович. ФТП, 31, 1045 (1997).

[11] И.А. Бобровникова, М.Д. Вилисова, И.В. Ивонин, Л.Г.Лаврентьева, В.В. Преображенский, М.А. Путято, Б.Р. Семягин, С.В. Субач, С.Е. Торопов. ФТП, 37, 1072 (2003).

[12] L. Fu, H.H. Tan, M.B. Johnston, M. Gal, C. Jagadish. J. Appl. Phys., 85, 6786 (1999).

[13] O. Hulko, D.A. Thompson, J.G. Simmons. Semicond. Sci. Technol., 24, 045015 (2009).

[14] Yu.A. Danilov, M.N. Drozdov, Yu.N. Drozdov, A.V. Kudrin, O.V. Vikhrova, B.N. Zvonkov, I.L. Kalentieva, V.S. Dunaev. J. Spintronics and Magnetic Nanomater., 1, 82 (2012).

[15] L.M.C. Pereira, U. Wahl, S. Decoster, J.G. Correia, M.R. da Silva, A. Vantomme, J.P. Araújo. Appl. Phys. Lett., 98, 201905 (2011).

[16] R. Schulz, T. Korn, D. Stich, U. Wurstbauer, D. Schuh, W. Wegscheider, C. Schuller. Physica E, 40, 2163 (2008).

[17] Б.И. Болтакс. Дифбузия и точечные дефекты в полупроводниках (Л., Наука, 1972) с. 383.

[18] D.D. Nolte. J. Appl. Phys., 85, 6259 (1999).

[19] С.С. Хлудков, О.Б. Корецкая. Изв. вузов. Физика, 28 (1), 107 (1985).

[20] J.S. Tsang, C.P. Lee, S.H. Lee, K.L. Tsai, H.R. Chen. J. Appl. Phys., 77, 4302 (1995).

[21] K.W. Edmonds, P. Boguslawski, K.Y. Wang, R.P. Campion, S N. Novikov, N.R.S. Farley, B.L. Gallagher, C.T. Foxon, M. Sawicki, T. Dietl, M. Buongiorno Nardelli, J. Bernholc. Phys. Rev. Lett., 92, 037201 (2004).

[22] F. Tuomisto, K. Pennanen, K. Saarinen, J. Sadowski. Phys. Rev. Lett., 93, 055505 (2004).

[23] F. Matsukura, H. Ohno, T. Dietl. Handbook of Magnetic Materials, Elsevier, 14, 1 (2002).

[24] K. Lawniczak-Jablonska, J. Libera, A. Wolska, M.T. Klepka, P. Dluzewski, J. Bak-Misiuk, E. Dynowska, P. Romanowski, J.Z. Domagala, J. Sadowski, A. Barcz, D. Wasik, A. Twardowski, A. Kwiatkowski. Phys. Status Solidi B, 248, 1609 (2011).

Редактор Г.А. Оганесян 


\section{Thermal annealing effects on photoluminescence of the structures with InGaAs/GaAs quantum wells and low temperature delta-doped Mn GaAs layer}

I.L. Kalentyeva ${ }^{+}$, O.V. Vikhrova ${ }^{+}$, Yu.A. Danilov ${ }^{+}$, B.N. Zvonkov ${ }^{+}$, A.V. Kudrin ${ }^{+}$, M.N. Drozdov*

+ Physicotechnical Research Institute of Lobachevsky State University of Nizhny Novgorod, 603950 Nizhny Novgorod, Russia

* Institute for Physics of Microstructures,

Russian Academy of Science,

603950 Nizhny Novgorod, Russia

Abstract The effects of thermal isochronous annealing $\left(325-725^{\circ} \mathrm{C}\right)$ on the radiative properties of $\mathrm{InGaAs} / \mathrm{GaAs}$ heterostructures with low temperature delta-doped $\mathrm{Mn}$ grown by laser deposition GaAs layer were studied. We observed a decrease of the photoluminescence intensity and an increase of the quantum well ground transition energy with annealing temperature. The distribution of $\mathrm{Mn}$ atoms in the initial and annealed structures was obtained by secondary ion mass spectrometry. A qualitative model of observed effects which takes into account the diffusion of point defects (primarily gallium vacancies) from GaAs cap layer into structure and $\mathrm{Mn}$ diffusion in both directions on dissociation mechanism was discussed. Magnetization studies have shown that increment of room temperature ferromagnetic phase (presumably, MnAs clusters) in the GaAs cap layer occurs as result of thermal annealing. 